\title{
Structural simplification compromises the potential of common insectivorous bats to provide biocontrol services against the major olive pest Prays oleae
}

\author{
Ana Costa ${ }^{\mathrm{a}, 1}$, Bruno Silva ${ }^{\mathrm{a}, 1}$, Gerardo Jiménez-Navarro ${ }^{\mathrm{a}}$, Sílvia Barreiro ${ }^{\mathrm{a}}$, \\ Nereida Melguizo-Ruiz ${ }^{\mathrm{a}}$, Javier Rodríguez-Pérez ${ }^{\mathrm{a}}$, Sasha Vasconcelos ${ }^{\mathrm{b}, \mathrm{c}}$, Pedro Beja ${ }^{\mathrm{b}, \mathrm{c}}$, \\ Francisco Moreira $^{\mathrm{b}, \mathrm{c}}$, José M. Herrera ${ }_{*}^{\mathrm{a},{ }_{*}, 1}$ \\ ${ }^{a}$ Mediterranean Institute for Agriculture, Environment and Development, University of Évora, Casa Cordovil, 2nd Floor, R. Dom Augusto Eduardo Nunes 7, 7000 - 651 \\ Évora, Portugal \\ ${ }^{\mathrm{b}}$ Centro de Ecologia Aplicada "Professor Baeta Neves" (CEABN), InBIO, InstitutoSuperior de Agronomia, Universidade de Lisboa, Tapada da Ajuda, $1349-017$ Lisboa, \\ Portugal \\ ${ }^{\mathrm{c}}$ Centro de Investigação em Biodiversidade e Recursos Genéticos (CIBIO), InBIO, Universidade do Porto, Campus Agrário de Vairão, $4485-601$ Vairão, Portugal
}

\section{A R T I C L E I N F O}

\section{Keywords:}

Biocontrol services

Foraging

Landscape structure

Olive groves

Insect pests

\begin{abstract}
A B S T R A C T
Crop production intensification often leads to the structural simplification of production systems. This structural simplification is expected to have strong impacts on biodiversity and the provisioning of ecosystem services, but information about this topic is scarce. For instance, no information exists for Mediterranean olive (Olea europaea) groves, despite olive farming representing a significant share of the agricultural sector in some European countries. We investigated the impact of in-farm and landscape-level structural simplification on the potential of three common insectivorous bats (i.e., Pipistrellus kuhlii, P. pygmaeus and P. pipistrellus) to provide biocontrol services against one of the most harmful olive pests worldwide, the olive fruit moth Prays oleae. Bats and insect surveys were both carried out in olive groves representing increasing levels of structural simplification and during three sampling seasons (spring, summer and autumn). At grove-level, structural simplification was considered as resulting from reduced planting pattern variability (i.e., tree and row spacing) and tree features (diameter at breast height, height of the trunk and canopy area), while at landscape level was considered as resulting from reduced land-cover types. We found that the Kuhl's pipistrelle was the most frequently recorded species in all types of olive groves and seasons. Moreover, the activity levels of pipistrelle bats as a whole significantly decreased with the structural simplification of olive groves. The abundance of $P$. oleae was highest at intermediate levels of structural simplification, irrespective of the season. Forest cover in the surrounding landscape had a significant positive influence on the activity levels of $P$. kuhlii, and a significant and negative influence on the abundance of $P$. oleae. Our study demonstrates that structural simplification differentially influences the activity patterns of both insectivorous bats and insect pests within olive groves. Moreover, it suggests that structural simplification may strongly compromise biocontrol services provided by bats on the major olive pest $P$. oleae.
\end{abstract}

\section{Introduction}

In the Euro-Mediterranean region, olive (Olea europaea L. 1753) farming represents a significant share of the land surface devoted to agriculture, being by far one of the most striking landscape features throughout this broad region. With a planted area exceeding eight million hectares (i.e., roughly $4 \%$ of the available agricultural area) and a mean annual production of 10 million tonnes (roughly three quarters of global production), the Euro-Mediterranean region is currently the largest olive producing region in the world (Eurostat, 2012). Traditionally, olive farming used low-impact management practices, including a highly spatial variability in both planting patterns (i.e., distance between olive trees along rows and distance between tree rows) and tree features features (i.e., diameter at breast height, height of the

\footnotetext{
* Corresponding author.

E-mail address: herreramirlo@gmail.com (J.M. Herrera).

${ }^{1}$ These authors contributed equally to this manuscript.
} 
(a)

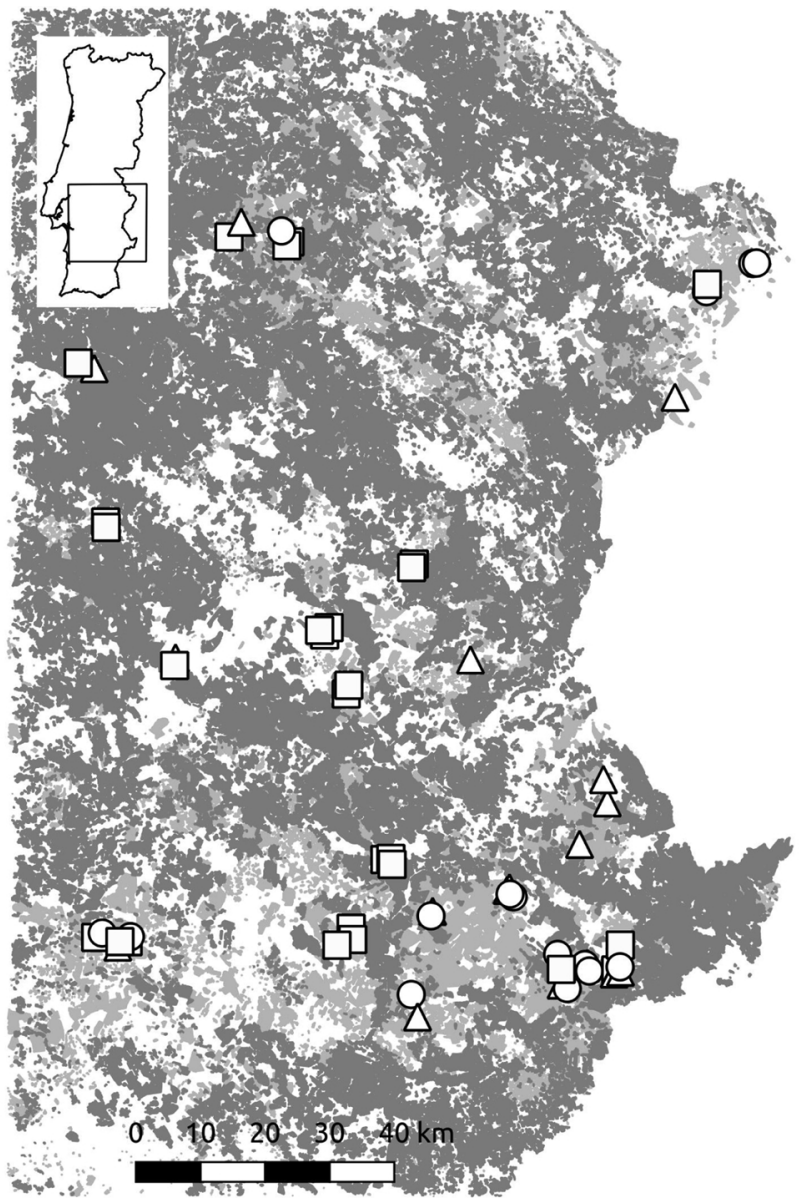

(b)

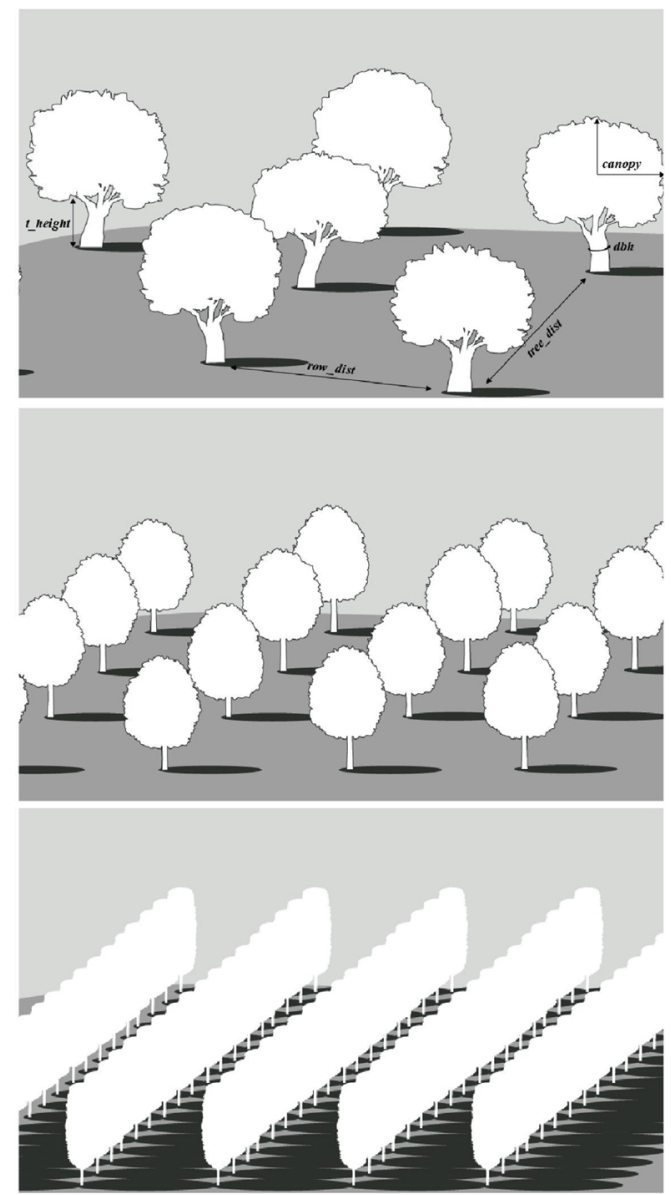

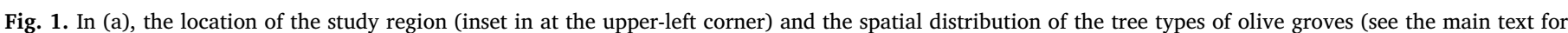

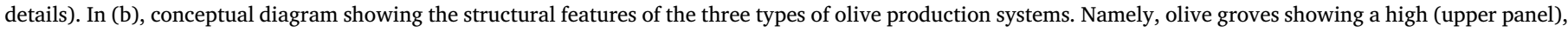

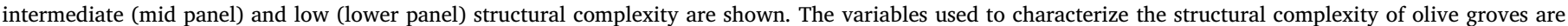
represented within the upper panel in (b).

trunk and canopy area). However, the increasing global demand for olive oil as well as the assignment of agricultural subsidies directly coupled with production levels during last decades, prompted the intensification of management practices and, in consequence, the structural simplification of both olive groves and the landscapes in which they are embedded through a homogenization of land cover types (Beaufoy, 2001).

Despite the widely demonstrated pervasive impacts on the structural simplification of production landscapes on biodiversity (Benton et al., 2003) and, to a much lesser extent, on biodiversity-mediated ecosystem processes (Gossner et al., 2016), research explicitly focused on olive groves is surprisingly scarce. Consequently, management know-how for the conservation of biodiversity in olive groves is still a key challenge, particularly if we aim to benefit from ecosystem services delivered by wild species (Baumgärtner, 2007). One such ecosystem services is biocontrol, which can be defined as the impact of wild species (biocontrol agents) on the population density of crop pests. A growing body of work demonstrates that insectivorous bats are very effective at suppressing agricultural pests (Riccucci and Lanza, 2014; Williams-Guillén et al., 2016; Maas et al., 2016; Russo et al., 2018). Ultimately, this provides an undeniable argument for the conservation of these species as, far from being trivial, efficient pest management is widely recognized as being one of the major challenges for fostering economically profitable olive farms, particularly across the Mediterranean Basin (Ponti et al., 2014).

The olive fruit moth, Prays oleae Bernard 1788 (Lepidoptera: Praydidae), is one of the most harmful olive pests worldwide. $P$. oleae is a monophagous species with three annual generations, each of which is synchronized with the seasonal growth of specific plant structures, namely leaves, flowers and fruits (Gonzalez et al., 2015). It has recently been recorded in the diets of insectivorous bats (Vanessa Mata, Personal Communication), though their role as biocontrol agents against this specific crop pest is still far from understood. However, previous research carried out in the same study region demonstrates that olive farming intensification negatively affects bat assemblage composition and activity levels (Herrera et al., 2015), suggesting concomitant deleterious impacts on biocontrol services against $P$. oleae and possibly other major olive (insect) pests such as the olive fruit fly Bactrocera oleae Rossi 1790 (Diptera: Tephitidae). However, the study was restricted to a particular sampling season (i.e., summer) and did not simultaneously assess the spatio-temporal distribution patterns of both bats and pests. Consequently, more research is needed not only to understand the impacts of management intensification on bats and the biocontrol services they provide, but also to determine the reliability and predictability of such impacts over time (Herrera and DoblasMiranda, 2013).

In the present study, we investigated the activity levels of three common insectivorous bat species (i.e., Kuhl's pipistrelle Pipistrellus kuhlii, soprano pipistrelle $P$. pygmaeus, and common pipistrelle $P$. pipistrellus) and the abundance patterns of $P$. oleae. Both bat and insect surveys were carried out in olive groves representing increasing levels of in-field and landscape structural simplification. At grove-level, structural simplification was considered as resulting from reduced planting pattern variability (i.e., tree and row spacing) and tree features 
(diameter at breast height, height of the trunk and canopy area), while at landscape level was considered as resulting from reduced land-cover types. Since bats adjust their foraging and activity levels according to their annual reproductive life cycle (e.g. Ciechanowski et al., 2010; Heim et al., 2016), and P. oleae has three seasonal peaks of abundance along its life cycle (see above), sampling surveys were performed during three consecutive seasons: spring, summer and autumn. By comparing the spatio-temporal patterns of activity of both insectivorous bats and insect pests, we aimed to determine whether the structural simplification of olive groves had an impact on the ability of bats to provide biocontrol services within olive groves. We expected a lower probability of bat-mediated biocontrol services with decreasing structural complexity, due to higher reductions in bat activity compared to pest activity, irrespectively of the sampling season (Williams-Guillén and Perfecto, 2011; Herrera et al., 2015).

\section{Material and methods}

\subsection{Study area}

This study was carried out in the region of Alentejo, southern Portugal (Fig. 1a), which is one of the most important olive growing regions in Europe (Eurostat, 2012). Regional climate is Mediterranean, which is characterized by mild and rainy winters and by warm and dry summers with temperatures commonly reaching $40^{\circ} \mathrm{C}$. The topography is flat, with altitude ranging between 100 and $400 \mathrm{~m}$ a.s.l. Natural and semi-natural vegetation throughout the study region mainly occurs in the form of extensive savanna-like forests composed largely of cork (Quercus suber L.) and holm-oak (Q. rotundifolia L.) trees in varying densities (Pinto-Correia et al., 2011). Other dominant land cover types include orchards of tree-like crops, mainly olive (Olea europaea L.), vineyards (Vitis vinifera L.) and open areas allocated to cattle grazing and cereal farming. Minor land cover types include timber plantations (mainly of Pinus pinaster L. and Eucalyptus spp.) and small human settlements.

\subsection{Sampling design and sampling site characterization}

Following a stratified random design, we selected 60 sampling points within 38 olive groves across the study region, to represent the greatest possible range of structural complexity. The maximum number of sampling points within a given olive grove was $n=2$, always ensuring a distance of 500 in-between them. Each olive grove was characterized using a set of structural characteristics describing both planting patterns and tree features. We used the distance between olive trees along rows (tree_dist), the distance between tree rows (row_dist), the diameter at breast height of olive trees $(d b h)$, the standard deviation of the diameter of the tree trunks ( $\left.d b h_{-} S D\right)$, height of the trunks (t_height), standard deviation of the height of the trunks (t_height $S D$ ), tree canopy area (canopy) and standard deviation of the tree canopy area (canopy_SD). Within each olive grove, we measured tree_dist, row_dist, dbh, theight tree and canopy area from at least ten replicates in order to obtain representative means and deviations (i.e., $d b h_{-} S D$, t_height_SD, canopy_SD) (Table 1). In doing so, two olive trees were randomly selected within $10 \mathrm{~m}$ buffers around each sampling point as well as around points $50 \mathrm{~m}$ further away following the four cardinal directions $\left(n_{2} \times 5=10\right)$. All the olive groves selected to perform this study - except organic groves $(n=12)$ - followed an integrated pest management strategy, whereby producers apply agrochemicals only when the population of pests is expected to cause economic loses that exceed the cost of agrochemicals treatment.

Olive groves were then assigned to single categories based on their structural features using a multivariate clustering method, the $k$-means clustering algorithm. The optimal number of clusters was obtained via the gap statistic (Tibshirani et al., 2001). This approach clearly identified three types of olive groves (Appendix A), corresponding to olive groves showing a (1) high structural complexity (henceforth referred to as HIGH; i.e., olive groves exhibiting the highest variability in both planting patterns and tree features), (2) intermediate structural complexity (MID; olive groves with intermediate variability) and (3) low structural complexity (LOW; exhibiting the lowest variability) (Table 1). Mean pairwise distances between sampling points located within olive groves classified as HIGH, MID and LOW were $69.6 \pm 2.6 \mathrm{~km}$ (range: $0.7-136.2$ ), $49.2 \pm 1.5 \mathrm{~km}$ (range: $0.8-117.7$ ) and $46.6 \pm 1.5 \mathrm{~km}$ (range: $0.5-126.5$ ), respectively (Fig. 1b). Based on the pairwise distances between the different types of olive groves, those classified as LOW and MID were, on average, closer to each other than between them and those classified as HIGH. This was related to the aggregated spatial distribution of HIGH olive groves, which show highest frequencies of occurrences in the Southern region of Alentejo.

To account for structural simplification at the landscape scale, we measured the amount of the two dominant land cover types around olive groves, olive groves and holm-oak (Quercus spp.) forests. Using a geographical information system (QGIS Development Team, 2016), the proportion of both land cover types were extracted within a $1 \mathrm{~km}$ circular buffer around each sampling point. The distance to the closest body of water was also estimated and used as a measure of water availability. The $1-\mathrm{km}$ radius was selected based on the foraging distances regularly covered by pipistrelle bats (Davidson-Watts and Jones, 2006).

\subsection{Bat monitoring}

Bats were monitored using ultrasound recording devices (Pettersson D500x; Pettersson Elektronik AB, Uppsala, Sweden) equipped with microphones with a sensitivity range of $10-190 \mathrm{kHz}$. Ultrasound samples were digitized at $300 \mathrm{kHz}$ with a resolution of 16 bits. During all surveys, we used the same auto-recording mode setting for $3 \mathrm{~s}$ without pre-trigger. Recordings were then used for species identification and determining species-specific activity levels. Bat surveys were conducted in spring (mid-April), summer (mid-June) and autumn (midSeptember), correspond to different periods of energy demand across their reproductive cycle; namely, pregnancy, lactation and mating (Heim et al., 2016).

In each sampling point, a single bat detector was mounted on a tripod at a height of about 1.5-2.0 meters from the ground, facing upwards at $45^{\circ}$ and orientated towards the space between rows of olive trees in order to maximize the number and recording quality of bat calls. Detectors were left for three consecutive nights at each sampling point per season, programmed to start recording $30 \mathrm{~min}$ before sunset and to finish $30 \mathrm{~min}$ after sunrise. Sampling was always conducted at temperatures exceeding $15^{\circ} \mathrm{C}$ and wind speed below $3.5 \mathrm{~m} \mathrm{~s}^{-1}$. Ten sampling points were simultaneously surveyed in each sampling round per season, ensuring at at least two sampling points placed within each type of olive grove (i.e., HIGH, MID and LOW).

Bat passes were identified to the lowest taxonomic level possible using a semi-automatic classification system, followed by a user validation as recommended by Russo and Voigt (2016), using published data on bat calls (Rainho et al., 2013). A bat pass was defined as a search-phase echolocation sequence of at least three consecutive echolocation calls of one bat (Brigham et al., 2004). Nineteen spectral and temporal parameters of bat echolocation calls were measured through a custom-built R script and the identification was performed by comparisons with a reference database using assemblages of neural networks. The database used is extensive and includes 16,000 individual calls from more than 1400 bats belonging to 24 species recorded in continental Portugal. Only bat passes successfully identified as belonging to one of the three pipistrelle species, that is, $P$. kuhlii, $P$. pygmaeus and $P$. pipistrellus, were considered. Pipistrelle bats were selected as they are by far the most abundant species within olive groves in our study region (Herrera et al., 2015). Bat activity was estimated as the number of bat passes by pooling the data from all the three 
Table 1

Description of variables used to characterize the structural properties of the olive groves, and summary statistics of these variables in olive groves showing high (HIGH; $\mathrm{n}=27$ ), medium (MID; $\mathrm{n}=18$ ) and low (LOW; $\mathrm{n}=15$ ) structural complexity (see Fig. 1 for details). Landscape-context variables estimated within a 1-km buffer around sampling points are also provided. Units are represented between parentheses.

\begin{tabular}{|c|c|c|c|c|c|}
\hline \multirow[t]{2}{*}{ Variables } & & \multirow[t]{2}{*}{ Description } & \multicolumn{3}{|c|}{ Structural complexity } \\
\hline & & & HIGH & MID & LOW \\
\hline \multirow[t]{8}{*}{ In-farm variables } & tree_dist & Distance between olive trees in the same row (m) & $7.96 \pm 0.41$ & $5.00 \pm 0.49$ & $1.37 \pm 0.16$ \\
\hline & row_dist & Distance between the rows of olive trees (m) & $8.35 \pm 0.32$ & $7.24 \pm 0.30$ & $3.41 \pm 0.17$ \\
\hline & $d b h$ & Diameter at breast height (m) & $1.12 \pm 0.06$ & $0.49 \pm 0.04$ & $0.27 \pm 0.01$ \\
\hline & $d b h \_S D$ & Standard deviation of dbh (m) & $0.30 \pm 0.04$ & $0.05 \pm 0.01$ & $0.03 \pm 0.00$ \\
\hline & canopy & Canopy area $\left(\mathrm{m}^{2}\right)$ & $19.96 \pm 1.49$ & $9.60 \pm 0.76$ & $1.46 \pm 0.18$ \\
\hline & canopy_SD & Standard deviation of canopy area $\left(\mathrm{m}^{2}\right)$ & $5.40 \pm 0.68$ & $2.01 \pm 0.18$ & $0.00 \pm 0.00$ \\
\hline & theight & Height of the trunk (m) & $0.89 \pm 0.05$ & $0.62 \pm 0.06$ & $0.45 \pm 0.03$ \\
\hline & t_height_SD & Standard deviation of trunk height (m) & $0.19 \pm 0.01$ & $0.11 \pm 0.01$ & $0.08 \pm 0.01$ \\
\hline \multirow[t]{2}{*}{ Landscape context variables } & F_cover & Proportion of forest cover (\%) & $14.07 \pm 3.96$ & $10.30 \pm 3.39$ & $8.28 \pm 3.80$ \\
\hline & O_cover & Proportion olive grove cover $(\%)$ & $59.39 \pm 4.64$ & $59.41 \pm 5.14$ & $52.62 \pm 6.60$ \\
\hline
\end{tabular}

sampling nights per sampling site, thereby obtaining a single measure per olive grove and season. Finally, bat-feeding activity was estimated as the number of feeding buzzes, which consist of specific call sequences emitted at high repetition rates and indicate prey capture attempts (Williams-Guillén and Perfecto, 2011).

\subsection{Pest monitoring}

We monitored the activity of $P$. oleae at each sampling point using a single Delta Trap (ECONEX; model TA118; $20 \times 28 \times 11.5 \mathrm{~cm}$ ) baited with synthetic sex pheromone [(Z)-7-14: Ald] contained in a polyethylene capsule. Delta traps were hung on a tree branch at c. $1.5 \mathrm{~m}$ from the ground on the southwest-facing side of the canopy. They were placed in the field for 15 days, overlapping with the periods of bat monitoring. Sampling was performed in mid-spring, early-summer and early-autumn, thereby coinciding with the peaks of abundance of this species (Gonzalez et al., 2015). At the end of each season, the number of captured $P$. oleae was counted and the total number of specimens per trap was used as a surrogate for site-specific abundance.

\subsection{Data analyses}

To test for differences in bat activity (i.e., number of bat passes recorded of each species) between the three types of olive groves, we used generalized linear mixed models (GLMMs) in which the type of olive grove (i.e., HIGH, MID and LOW) and season (i.e., spring, summer and autumn) were included as fixed effects. Forest and olive grove cover, as well as the distance to the closest body of water were included as co-variates. The identity of each olive grove was included as a random effect. A similar model structure was used to test for differences in the abundance of the $P$. oleae (i.e., number individuals caught per site). Due to skewed distributions, we applied a logarithmic transformation to both response variables and used a Gaussian distribution of the error for both. The most parsimonious models to describe the responses of species (including both bats and pests) were obtained by a backward stepwise procedure applied to both the random and fixed components (Hosmer and Lemeshow, 2000), with a stopping criterion of $p<0.05$. Benjamini-Hochberg post-hoc pairwise comparisons were applied to test for differences between types of olive groves and seasons (Benjamini and Hochberg, 1995). Visual inspections of residuals (qqplots and residual vs fitted plots) were performed to evaluate the assumptions of linearity and distributions of the models, and to detect potential outliers. Spatial independence between localities in model residuals was assessed applying a Mantel's test. A moderate (but significant) spatial residual trend was only found for $P$. pipistrellus during spring (Appendix B), and so we deemed unnecessary to account for spatial autocorrelation in the models. All statistical analyses were performed within "R" software environment, version 2.4.4. (http://www.r- project.org), using the functions lmer (R-package "lme4") for GLMMs (Bates et al., 2013), glht (R-package "multcomp") for post-hoc comparisons (Hothorn et al., 2008), kmeans (R-package "cluster") for clustering (Maechler et al., 2018) and mantel.rtest (R package "ade4") for spatial autocorrelation (Dray and Dufour, 2007).

\section{Results}

\subsection{Bat activity}

We recorded a total of 3,022 bat passes successfully identified as belonging to pipistrelle bats, including $P$. kuhlii ( $n=2049 ; 67.8 \%), P$. pygmaeus $(n=625 ; 20.7 \%)$ and $P$. pipistrellus $(n=348 ; 11.5 \%)$ (Table 2). A total of 214 feeding buzzes belonging to pipistrelle bats were also recorded, mostly belonging to $P$. kuhlii $(n=148 ; 69.2 \%)$, followed by $P$. pygmaeus $(n=47 ; 21.9 \%)$ and $P$. pipistrellus $(n=19$; $8.8 \%$ ). Due to the low number of feeding buzzes compared to that of bat passes and the significant positive correlation between both in all three species ( $P$. kuhlii, $r=0.86$; $P$. pygmaeus, $r=0.48$; $P$. pipistrellus, $r=0.65 ; p<0.001$ in all cases), we only used the number of bat passes for subsequent analyses.

We found significant differences between the different types of olive production systems in the activity levels of $P$. kuhlii and $P$. pygmaeus, but not for $P$. pipistrellus (Fig. 2; Table 3). The activity levels of both $P$. kuhlii and P. pygmaeus were consistently higher in olive groves classified as HIGH than in those classified as LOW. No differences between the different types of olive production systems in the activity levels of $P$. pipistrellus were found (Fig. 2).

We found no differences in P. kuhlii activity across seasons (Fig. 2). In contrast, activities of both $P$. pygmaeus and $P$. pipistrellus were higher in spring than in summer and autumn, but did not vary between summer and autumn (Fig. 2). Among landscape context variables, the only significant effect found corresponded to higher activity of $P$. kuhlii in groves surrounded by a higher amount of forest cover, (Table 3; Fig. 4).

\subsection{Pest activity}

The activity of $P$. oleae varied between olive production systems, with more specimens caught in MID than in LOW and HIGH olive groves (Fig. 3; Table 2). There were also seasonal effects, with more specimens caught in spring than in summer and autumn (Fig. 3; Table 3). Among the landscape context variables, the only significant effect found was an inverse relation between forest cover and the abundance of $P$. oleae caught (Fig. 4). There was a significant negative relation between the abundance of $P$. oleae and bat activity levels, particularly that of $P$. kuhlii (linear regression $t=-3.177 ; P<0.001$; Fig. 5). 
Table 2

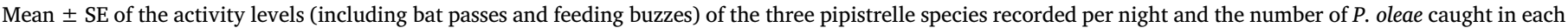
type olive grove across seasons.

\begin{tabular}{|c|c|c|c|c|c|c|c|c|c|}
\hline \multirow{4}{*}{ Species } & \multicolumn{9}{|l|}{ Season } \\
\hline & \multicolumn{3}{|l|}{ Spring } & \multicolumn{3}{|l|}{ Summer } & \multicolumn{3}{|l|}{ Autumn } \\
\hline & \multicolumn{3}{|c|}{ Structural complexity } & \multicolumn{3}{|c|}{ Structural complexity } & \multicolumn{3}{|c|}{ Structural complexity } \\
\hline & HIGH & MID & LOW & HIGH & MID & LOW & HIGH & MID & LOW \\
\hline \multicolumn{10}{|l|}{ Number of bat passes } \\
\hline Pipistrellus kuhlii & $24.7 \pm 5.9$ & $2.3 \pm 0.6$ & $2.9 \pm 1.1$ & $24.0 \pm 6.4$ & $5.1 \pm 1.6$ & $1.2 \pm 0.5$ & $15.8 \pm 2.9$ & $3.6 \pm 1.1$ & $2.5 \pm 0.5$ \\
\hline Pipistrellus pygmaeus & $5.0 \pm 1.3$ & $3.1 \pm 0.9$ & $2.6 \pm 1.6$ & $7.0 \pm 2.8$ & $2.8 \pm 1.4$ & $0.9 \pm 0.6$ & $3.6 \pm 1.1$ & $1.5 \pm 0.5$ & $0.8 \pm 0.2$ \\
\hline $\begin{array}{l}\text { Pipistrellus pipistrellus } \\
\text { Feeding buzzes }\end{array}$ & $3.1 \pm 0.9$ & $3.4 \pm 1.2$ & $2.4 \pm 1.0$ & $2.3 \pm 0.6$ & $1.5 \pm 0.8$ & $0.6 \pm 0.2$ & $1.1 \pm 0.4$ & $1.3 \pm 0.5$ & $0.6 \pm 0.2$ \\
\hline Pipistrellus kuhlii & $2.4 \pm 0.6$ & $0.2 \pm 0.1$ & $0.2 \pm 0.1$ & $1.5 \pm 0.8$ & $0.1 \pm 0.0$ & $0.0 \pm 0.0$ & $0.8 \pm 0.2$ & $0.2 \pm 0.1$ & $0.0 \pm 0.0$ \\
\hline Pipistrellus pygmaeus & $0.7 \pm 0.3$ & $0.2 \pm 0.1$ & $0.7 \pm 0.5$ & $0.0 \pm 0.0$ & $0.1 \pm 0.1$ & $0.0 \pm 0.0$ & $0.1 \pm 0.1$ & $0.1 \pm 0.0$ & $0.0 \pm 0.0$ \\
\hline $\begin{array}{l}\text { Pipistrellus pipistrellus } \\
\text { Number of individuals }\end{array}$ & $0.1 \pm 0.0$ & $0.3 \pm 0.2$ & $0.0 \pm 0.0$ & $0.0 \pm 0.0$ & $0.0 \pm 0.0$ & $0.1 \pm 0.0$ & $0.0 \pm 0.0$ & $0.1 \pm 0.0$ & $0.1 \pm 0.0$ \\
\hline Prays oleae & $194.2 \pm 52.5$ & $787.3 \pm 100.0$ & $479.4 \pm 65.1$ & $295.7 \pm 50.0$ & $569.3 \pm 118.6$ & $460.2 \pm 101.6$ & $101.3 \pm 15.6$ & $307.3 \pm 46.4$ & $170.4 \pm 31.3$ \\
\hline
\end{tabular}

\section{Discussion}

We investigated the activity levels of three common insectivorous bats (i.e., Pipistrellus kuhlii, P. pygmaeus and P. pipistrellus) in three types of olive production systems representative of high, intermediate and low structural complexity, during spring, summer and autumn. By simultaneously investigating the activity levels of a major olive pest, the olive fruit moth Prays oleae, potential knock-on effects on the ability of bats to provide natural pest control services were also explored. Overall, we found that the structural simplification of olive groves was associated with lower bat activity levels, while the activity of $P$. oleae reached a peak in groves with intermediate structural complexity. The structural simplification of the landscape context as resulting from reductions in natural cover area was related to decreased bat activity
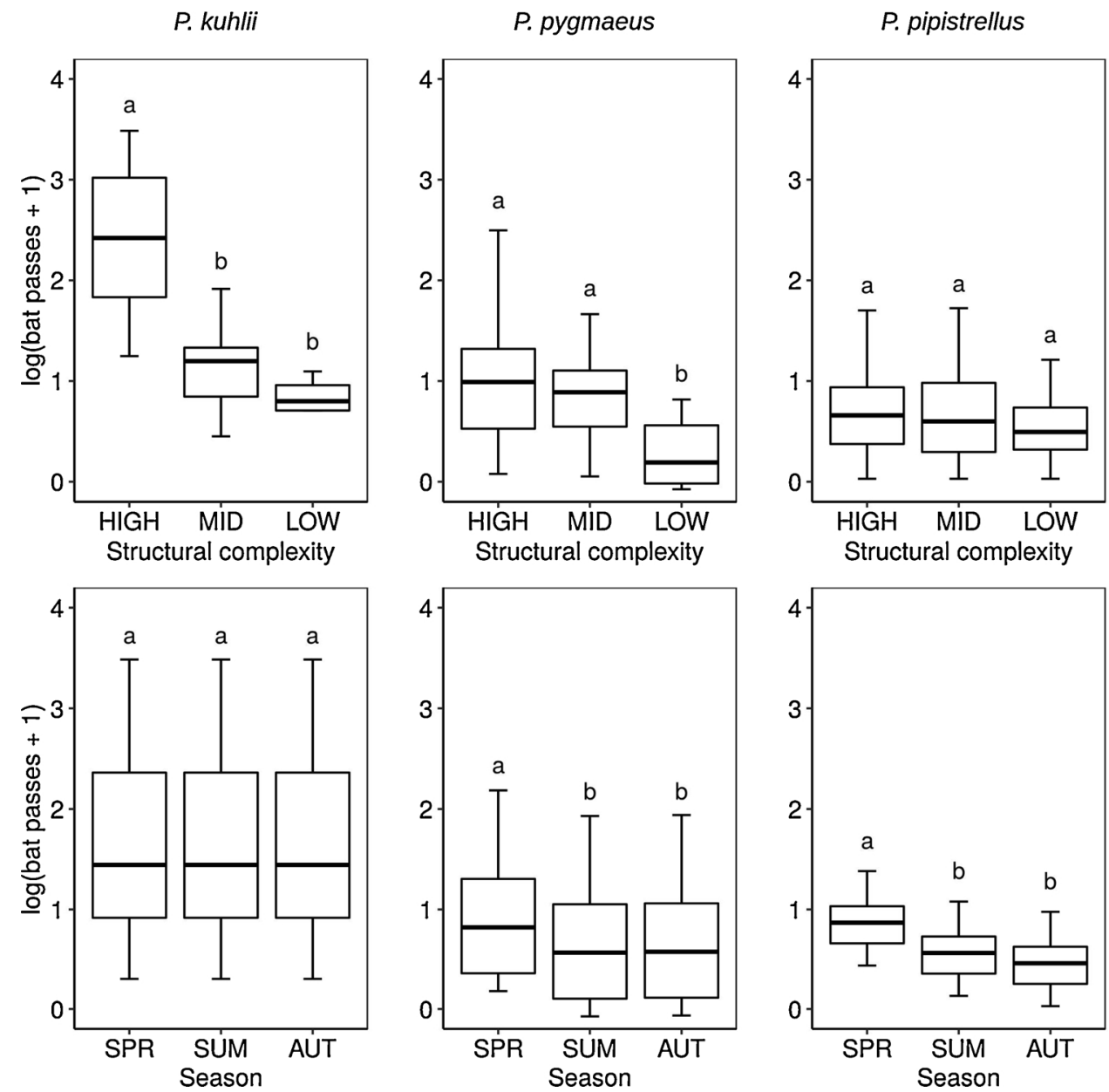

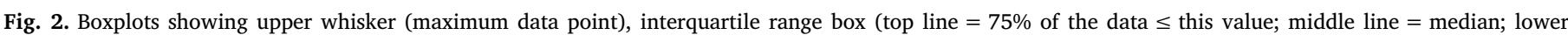

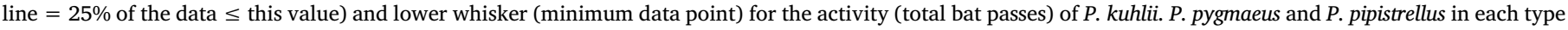

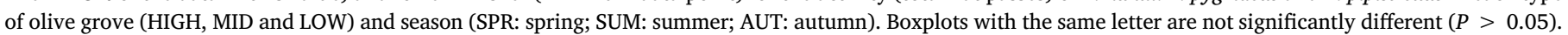


Table 3

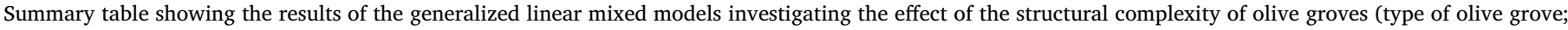

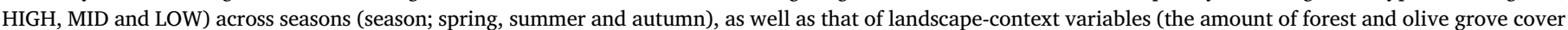

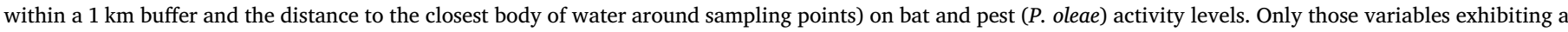

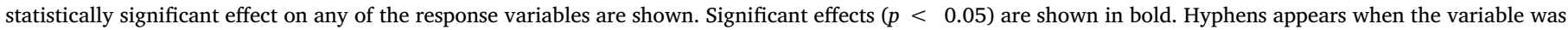
not included.

\begin{tabular}{|c|c|c|c|c|c|c|c|c|c|c|c|c|}
\hline & \multicolumn{3}{|c|}{ Pipistrellus kuhlii } & \multicolumn{3}{|c|}{ Pipistrellus pygmaeus } & \multicolumn{3}{|c|}{ Pipistrellus pipistrellus } & \multicolumn{3}{|c|}{ Prays oleae } \\
\hline & $\chi^{2}$ & d.f & $p$-value & $\chi^{2}$ & d.f & $p$-value & $\chi^{2}$ & d.f & $p$-value & $\chi^{2}$ & d.f & $p$-value \\
\hline Type of olive grove & 33.32 & 2 & $<0.001$ & 9.70 & 2 & 0.003 & - & - & - & 11.03 & 2 & 0.004 \\
\hline Season & - & - & - & 7.29 & 2 & 0.027 & 11.24 & 2 & 0.004 & 15.99 & 2 & $<0.001$ \\
\hline Forest cover & 4.43 & 1 & 0.035 & - & - & - & - & - & - & 13.42 & 1 & $<0.001$ \\
\hline Marginal $r 2$ & 0.30 & & & 0.11 & & & 0.04 & & & 0.26 & & \\
\hline
\end{tabular}

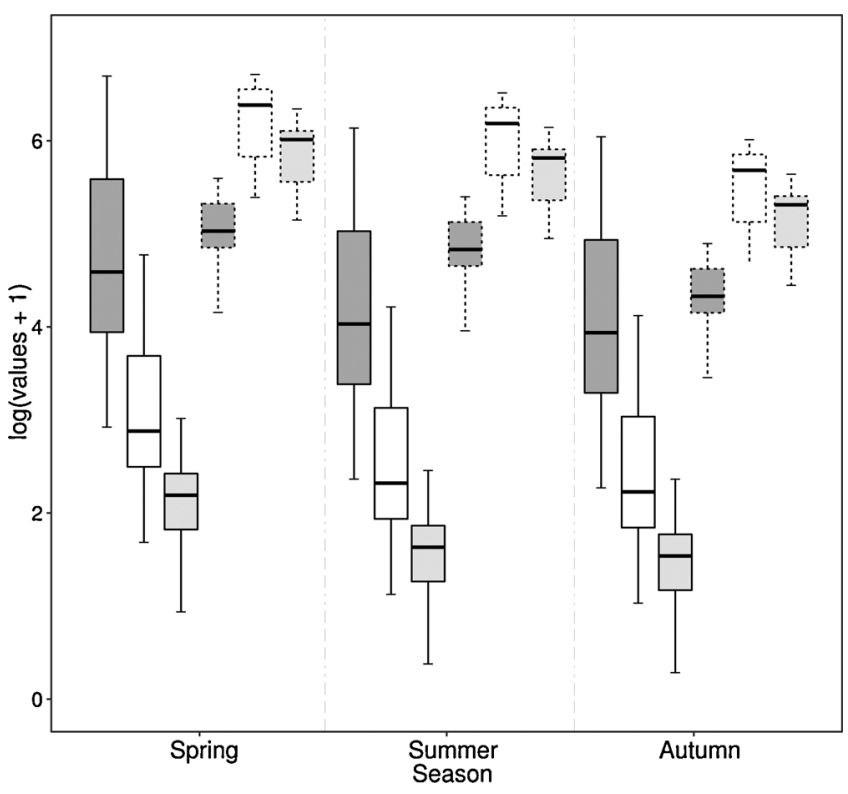

Fig. 3. Boxplots showing the maximum, interquartile range and minimum number of total bat passes (continuous line) and the number of specimens of Prays oleae (dashed line) caught in olive groves. Data are reported for the different types of olive groves; that is, olive groves showing a high (HIGH; darkgrey boxplots), intermediate (MID; white boxplots) and low (LOW; light-grey boxplots) structural complexity, and for the different seasons.

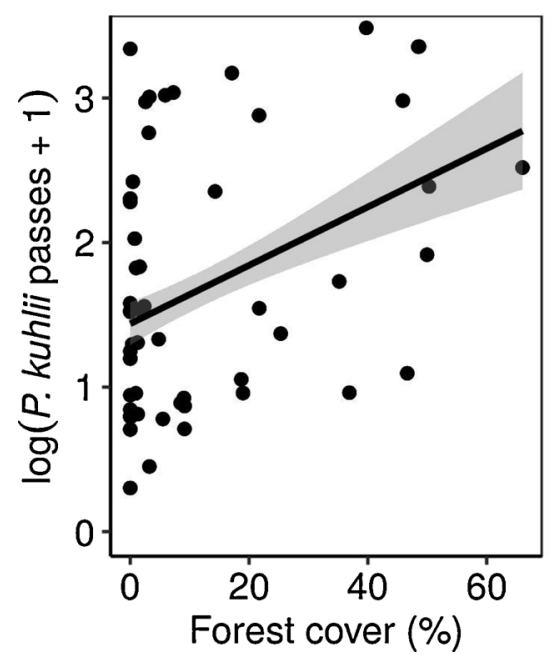

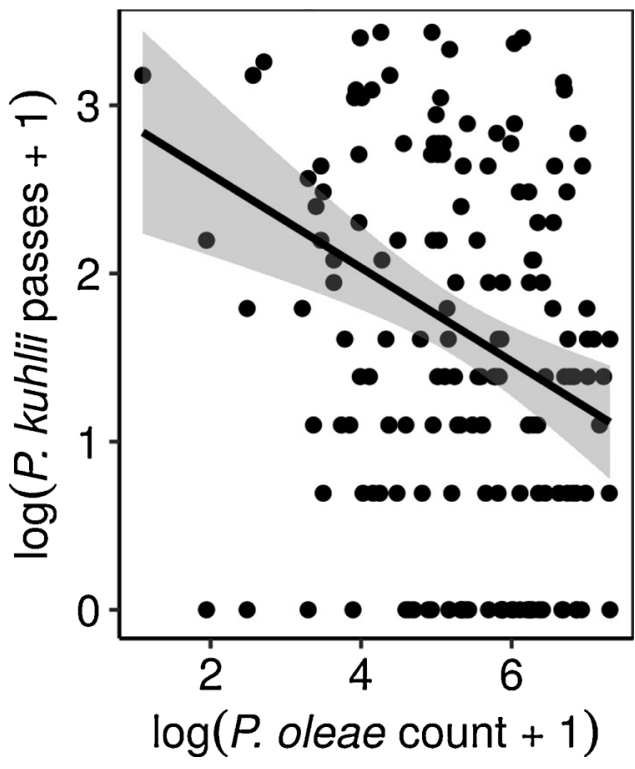

Fig. 5. Linear relationship between the abundance of $P$. oleae and the activity levels of $P$. kuhlii. The shadow area corresponds to the \pm 0.95 confidence intervals.

levels and increased pest abundance. We therefore suggest that the structural simplification at both in-farm and landscape-level may compromises the potential of bats to provide biocontrol services on the major olive pest $P$. oleae.

The overall activity of pipistrelle bats we found in olive groves from

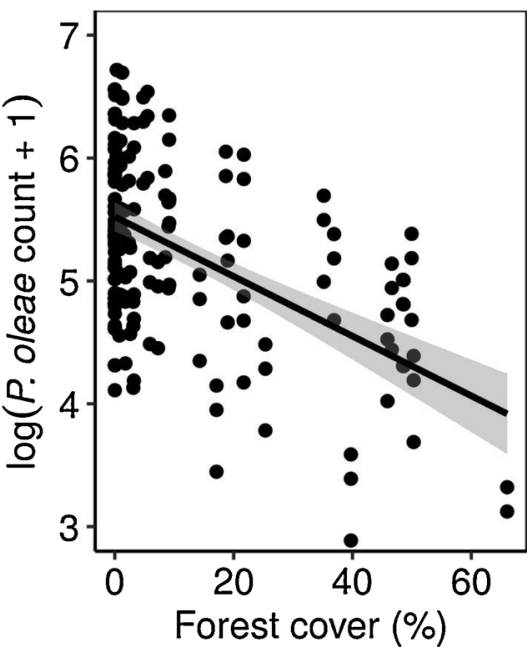

Fig. 4. Linear relationship between forest cover and the activity levels of $P$. kuhlii (left panel) and that of $P$. oleae (right panel). The shadow area corresponds to the \pm 0.95 confidence intervals. 
the region of Alentejo is comparatively much lower than that reported in natural habitats (Costa et al., 2018). However, they are remarkably similar to those recorded in other production systems in which pipistrelle bats are suggested to provide biocontrol services efficiently (PuigMontserrat et al., 2015). This suggest that, at least in structurally complex olive groves, pipistrelle bats could as efficient biocontrol agents against $P$. oleae. This is particularly true for $P$. kuhlii, as this species was by far the most frequently recorded across seasons and irrespectively of the structural features of olive groves. Indeed, Kuhl's pipistrelle has been previously found to be particularly active in olive groves (Davy et al., 2007; Herrera et al., 2015), thereby suggesting that it may contribute more to the provision of biocontrol services against olive insect' pests than the co-occurring $P$. pygmaeus and $P$. pipistrellus which were seldom recorded in olive groves irrespective of their structural properties and season of the year.

Despite its higher prevalence, even the activity of $P$. kuhlii decreased along the structural simplification gradient. Our results therefore closely match previous research that demonstrates a robust negative impact of landscape simplification on the activity levels of insectivorous bats in production systems (Wickramasinghe et al., 2004; Kelly et al., 2016; Kahnonitch et al., 2018). In our study system, structurally complex olive groves were characterized by exhibiting strong variations in planting pattern, something that ultimately would provide a suitable spatial framework for bats (Fuentes-Montemayor et al., 2011; Ducci et al., 2015). For instance, longer distances between trees and lower tree cover density could facilitate their foraging activity (Erickson and West, 2003). Conversely, as tree cover become denser and spatially cluttered, flight maneuverability decreases, thereby reducing the likely of bats entering the olive groves (Herrera et al., 2015). Moreover, the availability of old trees - which commonly exhibit natural holes that are often used by bats as roosting sites - markedly increases in structurally complex olive groves making them comparatively more attractive for bats. This response pattern has actually been previously observed when investigating bat activity in managed and unmanaged chestnut orchards in southern Switzerland. Managed chestnut orchards were much less dense and cluttered, thereby showing low tree and row spacing, and total bat foraging (including that of pipistrelle bats) was five times higher compared to that recorded in unmanaged ones (Obrist et al., 2011).

Unlike bats, we found that the abundance of $P$. oleae was higher structural simple olive groves (LOW) than in structurally complex (HIGH) olive groves, exhibiting a slight peak in olive groves exhibiting intermediate levels of structural complexity (MID). This response patterns is important because reduced food-resource availability has also been suggested to contribute to decreased bat activity with increasing structural simplification of olive groves (Herrera et al., 2015). Unfortunately, we lack data on insect availability at community-level that would allow us to understand how trophic preferences drive the species-specific foraging patterns of bats (Wickramasinghe et al., 2004). In this context, our results suggest that structural complexity (rather than prey availability) is a key factor affecting the activity of insectivorous bats in olive groves (Erickson and West, 2003; Obrist et al., 2011), but this needs to be confirmed through additional research. Nevertheless, we are confident that the abundance of $P$. oleae in each olive grove might well be used as a surrogate of local food resource availability as this species is expected to be the most abundant insect prey available for bats, particularly during the periods of adult emergence (note that up to 1500 specimens were caught per trap in some olive groves). Indeed, lepidopterans (particularly moths) are among the most frequently consumed prey by bats, including species morphologically very similar to $P$. oleae (Aizpurua et al., 2018). Our study therefore goes beyond existing works by demonstrating not only that the ability of bats to track food resources does not hinder them to suffer from the impact of structural simplification of olive groves (McCracken et al., 2012), but also that this response pattern may strongly compromise their potential to provide biocontrol services against crop pests.
Interestingly, we found that the abundance of $P$. oleae was negatively correlated with the amount of forest cover surrounding olive groves, irrespectively of their in-farm structural complexity. While we do not have any conclusive hypothesis, we suggest that rather than being a direct impact of forest cover on $P$. oleae, this response pattern may be explained by the influence that forest cover might have on its natural enemies, including not only bats but also other vertebrate and invertebrate species. Indeed, activity levels of insectivorous bats, particularly $P$. kuhlii, significantly increased with increasing forest cover (Fig. 4). Moreover, a significant negative relationship was found between the abundance of $P$. oleae and the activity levels of Kuhl's pipistrelles (Fig. 5). Thus, by favoring the presence of bats, forest cover may impact the population density of $P$. oleae and even stimulate lower reproductive rates in the moth, making a further contribution to its biological control (Puig-Montserrat et al., 2015). The positive influence that forest cover has on bats is well known. Such is the case, that the amount of remnant natural vegetation is considered a critical factor that determine assemblage composition and activity levels of bats within production landscapes. Thus, natural vegetation increases not only the likelihood of bats entering olive plantations but also their foraging activity, rising the potential of bats to provide biocontrol services (McCracken et al., 2012).

\subsection{Management implications}

Our work suggests that the structural complexity of olive groves is undoubtedly important to maintain the suitability of olive groves as foraging habitats for common insectivorous bats. Moreover, a focus on the influence of surrounding woody cover reflects species' specific requirements that are not provided by olive groves at the landscape scale. Halting reductions in bat activity levels as resulting from both in-field (through decreasing structural complexity) and landscape-scale (through reduced diversity of land-cover types) simplification, is therefore pivotal not only to the long-term conservation of bats, but probably also to the maintenance of bat-mediated biocontrol services against the major olive pest Prays oleae. We acknowledge that increases in the structural complexity of olive groves and/or the addition of woody vegetation is often not a feasible management strategy for growers in intensive agricultural systems (Olimpi and Philpott, 2018). However, we suggest that including a complementary focus on improving the quality of olive groves as foraging habitat for bats offers additional management options. For example, we advocate an integrated land-management approach aiming not only to maintain, but also to increase, the presence of scattered trees throughout olive monocultures. In our study region, both cork (Quercus suber L.) and holm-oak ( $Q$. rotundifolia L.) trees are excellent candidates. Far from being trivial, paddock trees and other small-sized remnants of original cover have been shown to disproportionately influence the persistence of many vertebrate species in agricultural landscapes, including bats (Herrera et al., 2016). The proportion of woody cover per surface unit to ensure the ecological sustainability of olive groves without compromising their economic profitability is, however, an open question that must be investigated in depth. Agri-environmental schemes in this culture should consider these proposals to ensure that growers continue to benefit from bat-mediated pest-suppression services.

To conclude, we recognize that our approach draws parallels between structural simplification and management intensification. Such is the case, that the three different types of olive groves that resulted from our classification closely fits a gradient of management intensification (Herrera et al., 2015). Thus, olive groves classified as HIGH would correspond to traditional olive farms, a low-intensity production system associated with big old trees, growing at low densities, giving small yields which receive relatively low inputs of agrochemicals; MID olive groves would represent semi-intensive olive farms, which is an intermediate farming practice between the 'traditional' and 'intensive' systems; and LOW olive groves would represent intensive olive farms, 
which are characterized by a high density of trees arranged in hedges, frequent fertilization and mechanical pruning, the use of several seasonal agrochemicals sprays for pest control (Beaufoy, 2001).Ultimately, this may lead to confounding suspects between the effects resulting from the structural properties of olive groves and others factors such as, for example, the level of agrochemicals use, which increase markedly along the intensification gradient. To this respect, it should be noted that the response pattens we found in this study closely match to those reported by Herrera et al. (2015), a work in which both the structure and management intensity were simultaneously considered for the classification of olive groves. This strongly suggests that the structural features of olive groves are key for determining the response patterns of insectivorous bats over management-related variables. However, we suspect that management-related variables such as agrochemicals use could be even more important at influencing the abundance patterns of insect pests. Indeed, as suggested above, the comparatively lower abundance of $P$. oleae in structurally simple olive groves (and, in consequence, the most intensively managed ones) compared to those showing an intermediate structural complexity, probably resulted from an efficient pest control through the use of agrochemicals. In this way, we strongly encourage future research to disentangle the different effects resulting from management intensification to obtain a more clear picture of their relative impacts on bats and crop pests and, in turn, batmediated biocontrol services.

\section{Author contributions}

$\mathrm{JMH}, \mathrm{BS}$ and AC conceived and designed this research; BS, SB, GJ-N, NM-R, SV, AC and JMH collected field data; BS, AC and JMH analysed the data; JMH and AC wrote the paper. All authors reviewed and approved the final manuscript.

\section{Declaration of Competing Interest}

The authors declare no competing financial interests.

\section{Acknowledgements}

We thank the growers who participated in this study and allowed us set up research equipment on their farms. This work was funded by the Portuguese National Funding Agency for Science, Research and Technology (FCT) through the project PTDC/AAG-REC/6480/2014. The project ALT20-03-0145-FEDER-000008provided some support. Authors were supported by the FCT through the contract IF/00001/ 2015 (JMH), the contract IF/01053/2015 (FM), and the predoctoral fellowships SFRH/BD/137803/2018 (BS), SFRH/BD/133017/2017 (GJ-N) and SFRH/BD/121388/2016 (SV).

\section{References}

Aizpurua, O., Budinski, I., Georgiakakis, P., Gopalakrishnan, S., Ibañez, C., Mata, V., Rebelo, H., Russo, D., Szodoray-Paradi, F., Zhelyazkova, V., Zrncic, V., Gilbert, M.T.P., Alberdi, A., 2018. Agriculture shapes the trophic niche of a bat preying on multiple pest arthropods across Europe: evidence from DNA metabarcoding. Molec Ecol. 27, 815-825.

Bates, D., Maechler, M., Bolker, B., Walker, S., 2013. lme4: Linear Mixed-Effects Models Using Ei-Gen and S4 [Computer Software]. (R package version 1.0-4). http://CRAN. R-project.org $/$ package $=$ lme 4 .

Baumgärtner, S., 2007. The insurance value of biodiversity in the provision of ecosystem services. Nat. Resour. Model. 20, 087-127.

Beaufoy, G., 2001. EU Policies for Olive Farming. Unsustainable on All Counts. WWF \& BirdLife Joint Report.

Benjamini, Y., Hochberg, Y., 1995. Controlling the false discovery rate: a practical and powerful approach to multiple testing. J. R. Stat. Soc. B 57, 289-300.

Benton, T.G., Vickery, J.A., Wilson, J.D., 2003. Farmland biodiversity: is habitat heterogeneity the key? Trends Ecol. Evol. 18, 182-187.

Brigham, R.M., Kalko, E.K.V., Jones, G., Parsons, S., Limpens, H.J.G.A., 2004. Bat Echolocation Research: Tools, Techniques and Analysis. Bat Conservation International, Austin, Texas.

Ciechanowski, M., Zajac, T., Zielinska, A., Dunajski, R., 2010. Seasonal activity patterns of seven vespertilionid bat species in Polish lowlands. Acta Theriol. 55, 301-314.

Costa, P., Medinas, D., Silva, B., Mira, A., Guiomar, N., Sales-Baptista, E., Ferraz-deOliveira, M.I., Simões, M.P., Belo, A.B.F., Herrera, J.M., 2018. Cattle-driven forest disturbances impact ensemble composition and activity levels of insectivorous bats in Mediterranean wood pastures. Agroforest. Syst. 93, 1687-1699.

Davidson-Watts, I., Jones, G., 2006. Differences in foraging behavior between Pipistrellus pipistrellus (Schreber, 1774) and Pipistrellus pygmaeus (Leach, 1825). J. Zool. 268, 55-62.

Davy, C.M., Russo, D., Fenton, M.B., 2007. Use of native woodlands and traditional olive groves by foraging bats on a Mediterranean island: consequences for conservation. J. Zool. 273, 397-405.

Dray, S., Dufour, A.B., 2007. The ade4 package: implementing the duality diagram for ecologists. J. Stat. Softw. 22, 1-20.

Ducci, L., Agnelli, P., Di Febbraro, M., Frate, L., Russo, D., Loy, A., Carranza, M.L., Santini, G., Roscioni, F., 2015. Different bat guilds perceive their habitat in different ways: a multiscale landscape approach for variable selection in species distribution modelling. Landsc. Ecol. 30, 2147-2159.

Erickson, J.L., West, S.D., 2003. Associations of bats with local structure and landscape features of forested stands in western Oregon and Washington. Biol. Conserv. 109, 95-102.

Eurostat, 2012. Agricultural Production-Orchards. Available online: http://ec.europa. eu/eurostat/statistics-explained/index.php/Agricultural_production_-_orchards.

Fuentes-Montemayor, E., Goulson, D., Park, K.J., 2011. Pipistrelle bats and their prey do not benefit from four widely applied agri-environment management prescriptions. Biol. Conserv. 144, 2233-2246.

Gossner, M.M., Lowinsohn, T.M., Kahl, T., 2016. Land-use intensification causes multitrophic homogenization of grassland communities. Nature 540, 266-269.

Gonzalez, D., Cabral, J.A., Torres, L., Santos, M., 2015. A cohort-based modelling approach for managing olive moth Prays oleae (Bernard, 1788) populations in olive orchards. Ecol. Model 296, 46-56.

Heim, O., Schröder, A., Eccard, J., Jung, K., Voigt, C.C., 2016. Seasonal activity patterns of European bats above intensively used farmland. Agric. Ecosyst. Environ. 233 $130-139$.

Herrera, J.M., Doblas-Miranda, E., 2013. Land-cover change effects on trophic interactions: current knowledge and future challenges in research and conservation. Basic Appl. Ecol. 14, 1-11.

Herrera, J.M., Costa, P., Medinas, D., Marques, J.T., Mira, A., 2015. Community composition and activity of insectivorous bats in Mediterranean olive farms. Anim. Conserv. 18, 557-566.

Herrera, J.M., Salgueiro, P.A., Medinas, D., Costa, P., Encarnação, C., Mira, A., 2016. Generalities of vertebrate responses to landscape composition and configuration gradients in a highly heterogeneous Mediterranean region. J. Biogreogr. 43, 1203-1214.

Hosmer, D.W., Lemeshow, S., 2000. Applied Logistic Regression, 2nd edition. John Wiley \& Sons, Inc., New York.

Hothorn, T., Bretz, F., Westfall, P., 2008. Simultaneous inference in general parametric models. Biom. J. 50, 346-363.

Kahnonitch, I., Lubin, Y., Korine, C., 2018. Insectivorous bats in semi-arid agroecosystems - effects on foraging activity and implications for insect pest control. Agric. Ecosyst. Environ. 261, 80-92.

Kelly, R.M., Kitzes, J., Wilson, H., Merenlender, A., 2016. Habitat diversity promotes bat activity in a vineyard landscape. Agric. Ecosyst. Environ. 223, 175-181.

Maas, B., Karp, S.D., Bumrungsri, S., et al., 2016. Bird and bat predation services in tropical forests and agroforestry landscapes. Biol. Rev. 91, 1081-1101.

Maechler, M., Rousseeuw, P., Struyf, A., Hubert, M., Hornik, K., 2018. Cluster: Cluste Analysis Basics and Extensions. R Package Version 2.0.7-1.

McCracken, G.F., Westbrook, J.K., Brown, V.A., Eldridge, M., Federico, P., Kunz, T.H., 2012. Bats track and exploit changes in insect pest populations. PLoS One 7 (8), e43839.

Obrist, M.K., Rathey, E., Bontadina, F., Martinoli, A., Conedera, M., Christe, P., Moretti, M., 2011. Response of bat species to sylvo-pastoral abandonment. For. Ecol. Manage. 261, 789-798.

Olimpi, E.M., Philpott, S.M., 2018. Agroecological farming practices promote bats. Agric. Ecosyst. Environ. 265, 282-291.

Pinto-Correia, T., Ribeiro, N., Sá-Sousa, P., 2011. Introducing the montado, the corand holm oak agroforestry system of Southern Portugal. Agroforest. Syst. 82, 99-104.

Ponti, L., Gutierrez, A.P., Ruti, P.M., Dell'Aquila, A., 2014. Fine-scale ecological and economic assessment of climate change on olive in the Mediterranean Basin reveals winners and losers. Proc. Nat. Acad. Sci. 111, 5598-5603.

Puig-Montserrat, X., Torre, I., López-Baucells, A., Guerrieri, E., Monti, M.M., RàfolsGarcía, R., Ferrer, X., Gisbert, D., Flaquer, C., 2015. Pest control service provided by bats in Mediterranean rice paddies: linking agroecosystems structure to ecological functions. Mamm. Biol. 80, 237-245.

QGIS Development Team, 2016. QGIS Geographic Information System. Open Source Geospatial Foundation Project. http://qgis.osgeo.org.

Rainho, A., Alves, P., Amorim, F., Marques, J.T., 2013. Atlas dos Morcegos de Portugal Continental. Lisboa: Instituto de Conservação da Natureza e Florestas 76 pp + Annexes.

Riccucci, M., Lanza, B., 2014. Bats and insect pest control: a review. Vespertilio 17, 161-169.

Russo, D., Voigt, C.C., 2016. The use of automated identification of bat echolocation calls in acoustic monitoring: a cautionary note for a sound analysis. Ecol. Indic. 66, 598-602.

Russo, D., Bosso, L., Ancillotto, L., 2018. Novel perspectives on bat insectivory highlight the value of this ecosystem service in farmland: research frontiers and management implications. Agric. Ecosyst. Environ. 266, 31-38. 
Tibshirani, R., Walther, G., Hastie, T., 2001. Estimating the number of clusters in a data set via the gap statistic. J. R. Stat. Soc. 63, 411-423.

Wickramasinghe, L., Harris, S., Jones, G., Vaughan, N., 2004. Abundance and species richness of nocturnal insects on organic and conventional farms: effects of agricultural intensification on bat foraging. Conserv. Biol. 18, 1283-1292.

Williams-Guillén, K., Olimpi, E., Maas, B., Taylor, P.J., Arlettaz, R., 2016. Bats in the anthropogenic matrix: challenges and opportunities for the conservation of
Chiroptera and their ecosystem services in agricultural landscapes. In: Voigt, C.C., Kingston, T. (Eds.), Bats in the Anthropocene: Conservation of Bats in a Changing World. Springer, Cham, USA, pp. 151-186.

Williams-Guillén, K., Perfecto, I., 2011. Ensemble composition and activity levels of insectivorous bats in response to management intensification in coffee agroforestry systems. PLoS One 6, e16502. 